\title{
Vitamin D-rich marine Inuit diet and markers of inflammation - a population-based survey in Greenland
}

\author{
L. K. Schæbel ${ }^{1,2,3} *$, E. C. Bonefeld-Jørgensen ${ }^{1}$, P. Laurberg ${ }^{3}$, H. Vestergaard ${ }^{4}$ and S. Andersen ${ }^{2,5,6}$ \\ ${ }^{1}$ Department of Public Health, Centre for Arctic Health, Aarbus University, Aarhus, Denmark \\ ${ }^{2}$ Department of Clinical Medicine, Arctic Health Research Centre, Aalborg University, Aalborg, Denmark \\ ${ }^{3}$ Endocrine Research Unit, Department of Clinical Medicine, Aalborg University, Aalborg, Denmark. \\ ${ }^{4}$ The Novo Nordisk Foundation Center for Basic Metabolic Research, Section of Metabolic Genetics, Faculty of Health and Medical Sciences, \\ University of Copenhagen, Copenhagen, Denmark \\ ${ }^{5}$ Department of Geriatric and Internal Medicine, Aalborg University Hospital, Aalborg, Denmark \\ ${ }^{6}$ Department of Internal Medicine, Queen Ingrid's Hospital, Nuuk, Greenland
}

(Received 4 September 2015 - Accepted 12 October 2015)

Journal of Nutritional Science (2015), vol. 4, e40, page 1 of 8

doi:10.1017/jns.2015.33

\section{Abstract}

The traditional Inuit diet in Greenland consists mainly of fish and marine mammals, rich in vitamin D. Vitamin D has anti-inflammatory capacity but markers of inflammation have been found to be high in Inuit living on a marine diet. Yet, the effect of vitamin D on inflammation in Inuit remains unsettled. This led us to investigate the association between vitamin D and markers of inflammation in a population with a high intake of a marine diet. We studied 535 Inuit and non-Inuit living in West and East Greenland. Information concerning dietary habits was obtained by interview-based FFQ. Blood samples were drawn for analysis of 25-hydroxyvitamin D, high-sensitivity C-reactive protein (hsCRP) and chitinase-3-like protein 1(YKL40). Participants were divided into three groups based on degree of intake of the traditional Inuit diet. The diet groups (Inuit diet/mixed diet/imported foods) were associated with vitamin $\mathrm{D}$ levels in serum (74.2, $69 \cdot 8$ and $52.9 \mathrm{~nm} ; P<0 \cdot 001)$, hsCRP (1.6, 1.4 and 1.3 mg/l; $P=0.002)$ and YKL-40 (130, 95 and $61 \mathrm{ng} / \mathrm{ml} ; P<0 \cdot 001$ ), respectively. YKL-40 level decreased with rising vitamin D level in Inuit (Inuit diet $P=0 \cdot 002$; mixed diet $P=0 \cdot 011$ ). YKL-40 was lower in groups with higher vitamin D levels after adjusting for other factors known to influence inflammation $(P<0 \cdot 001)$. This was not seen for hsCRP. In conclusion, vitamin D and markers of inflammation vary in parallel with the intake of the marine Inuit diet. Vitamin D levels were inversely associated with YKL-40 levels, but no association with hsCRP was found. The hypothesised anti-inflammatory effect of vitamin D was not supported. Other factors in the marine diet may be speculated to influence inflammation.

Key words: Inuit marine diet: Vitamin D: Inflammation: Arctic Greenland: Population-based studies: Dietary surveys and nutritional epidemiology

IHD and its complications are major causes of death ${ }^{(1)}$. The atherosclerotic process that leads to IHD has been investigated for decades, and it is now widely recognised that atherosclerotic lesions represent a series of cellular and molecular responses where inflammation plays an important role ${ }^{(2)}$.

The progression of atherosclerosis is linked to an imbalance of inflammatory and anti-inflammatory activities ${ }^{(2)}$. This can be estimated by measuring markers of inflammation in serum. Chitinase-3-like protein 1 (also known as YKL-40) is an emerging marker of inflammation secreted by macrophages in the human atherosclerotic vessel wall ${ }^{(3)}$. YKL-40 has been demonstrated to be an indicator of inflammation involved in the presence and progression of coronary artery disease ${ }^{(4,5)}$. C-reactive protein (CRP) is another marker of inflammation.

Abbreviations: CRP, C-reactive protein; hsCRP, high-sensitivity CRP; POPs, persistent organic pollutants; YKL-40, chitinase-3-like protein 1.

* Corresponding author: Dr L. K. Schæbel, email lohos@rn.dk

(C) The Author(s) 2015. This is an Open Access article, distributed under the terms of the Creative Commons Attribution licence (http://creativecommons.org/licenses/by/4.0/), which permits unrestricted re-use, distribution, and reproduction in any medium, provided the original work is properly cited 
It is an acute-phase reactant produced by hepatocytes stimulated by IL-6. CRP is known to reflect the inflammatory processes in the $\operatorname{arteries}^{(2)}$.

Vitamin D influences the inflammatory response by inhibiting the inflammatory process. This inhibition is mediated by down-regulating pro-inflammatory cytokines and up-regulating anti-inflammatory cytokines ${ }^{(6)}$. Vitamin D deficiency has been shown to be associated with inflammation ${ }^{(7)}$ as well as an increased risk of CVD and mortality ${ }^{(8,9)}$.

A low occurrence of IHD among pre-Western Inuit ${ }^{(10)}$ was linked to a diet with a high content of traditional Inuit food items that consisted mainly of free-living fish and marine mammals ${ }^{(11)}$. However, the occurrence of IHD among Inuit in Greenland has increased ${ }^{(12)}$ along with changes in diet and lifestyle ${ }^{(13,14)}$.

The traditional Inuit diet is a rich source of vitamin D and a decreased intake of traditional Inuit diet implies a decreased level of vitamin D in the population ${ }^{(15)}$. Furthermore, the Inuit diet associates with markers of inflammation ${ }^{(16)}$ and this association may be speculated to be influenced by vitamin $\mathrm{D}$ from the Inuit diet.

This led us to investigate the association between the intake of the traditional marine Greenlandic diet and vitamin D levels in plasma and two different markers of inflammation among Inuit and non-Inuit living in East and West Greenland with marked differences in dietary habits. We further assessed if vitamin $\mathrm{D}$ might influence markers of inflammation in addition to other factors known to affect inflammation.

\section{Subjects and methods}

\section{Area of investigation}

Greenland has 56000 inhabitants, with approximately 1000 foreign citizens living and working in Greenland. Nuuk $\left(64.15^{\circ} \mathrm{N}, 51.35^{\circ} \mathrm{W}\right)$ in West Greenland is the capital of Greenland with just under 16000 inhabitants of whom $75 \%$ are Inuit (Eskimo) and $25 \%$ non-Inuit (Caucasians). Nuuk was established as a trading post under the Danish crown in 1728 and is now a modern city with access to a wide variety of food items, including take-aways that are supplementary to the traditional Greenlandic food items. In addition, a wide variety of imported food items is available in stores.

The Ammassalik district $\left(65 \cdot 35^{\circ} \mathrm{N}, 38 \cdot 00^{\circ} \mathrm{W}\right)$ of East Greenland was isolated until 1884 and is still difficult to reach by sea because of pack ice from the northern icecap. It is sparsely populated; there are less than 3000 inhabitants (93\% Inuit) in an area of $243000 \mathrm{~km}^{2}$. Tasiilaq is the main town of the Ammassalik district, which also includes five settlements. Tasiilaq has one store and five minor shops. The selection of imported food depends on sea ice and hence the opportunity for ships to call at the local harbour. Each of the settlements has one store with a limited selection that also depends on access by sea.

The capital city, town and settlements are all situated on fjords, which give the inhabitants access to the sea. This allows for both occupational and leisure time access to hunting and fishing.

\section{Subjects}

Participants were Inuit (Greenlanders) and non-Inuit (all Caucasian Danes), men and women, aged 50 to 69 years. The investigation was performed in Nuuk, Tasiilaq, and the settlements Tiniteqilaaq, Sermiligaaq, Kulusuk and Kuummiut in the Ammassalik district ${ }^{(13,15,16)}$. Settlements with less than fifteen inhabitants in the selected age group were not included for practical reasons ${ }^{(13)}$.

In Nuuk, names and addresses were obtained from the hospital registration system. A random sample of 480 was selected ( $25 \%$ of the total population aged 50 to 69 years).

In the Ammassalik district names and addresses were obtained from the National Civil Registration System in which every person living in Denmark, the Faeroe Islands and Greenland is recorded.

For all invited participants a letter of invitation was delivered by the local hospital porter or the nursing station attendant. Invitations were sent to non-responders three times. In all, 561 persons were invited and 535 (95\%) participated ${ }^{(13)}$.

In this study, an Inuit (Greenlander) was defined as a person born in Greenland with both parents born in Greenland as well.

This study was conducted according to the guidelines laid down in the Declaration of Helsinki and all procedures were approved by the Commission for Scientific Research in Greenland before the study was commenced (j. number 505-31). All subjects gave informed written consent, which was in Danish or Greenlandic by participant choice.

\section{Investigational procedures}

The study was conducted at the local hospital or nursing station or as home visits if requested. One of the doctors in the study performed a physical examination, which included measurement of height without shoes, weight in indoor clothing and recording of major disabilities. The National Civil Registration System was used to obtain information about sex and age. A questionnaire in either Danish or Greenlandic was completed by interview performed by a Greenlandic interpreter or one of the investigating doctors. The interview-based questionnaires were used to obtain information about lifestyle patterns and dietary habits. The same interpreter was used at all sites of investigation.

A venous blood sample was drawn at the visit using minimal tourniquet. The blood sample was separated and stored at $-20^{\circ} \mathrm{C}$ until analysis. Serum was missing in five participants.

\section{Dietary habits}

The FFQ included traditional Greenlandic food items (seal, whale, wild fowl, fish, reindeer, musk ox, hare and lamb) and imported food items (pre-cooked meals, potatoes, vegetables, butter, cheese, eggs and fresh fruit). For each food item, the participants were asked to categorise how frequently they had an intake of the particular food item - ranging from never to daily ${ }^{(13,15)}$.

Each item was then given a frequency score calculated as the average number of $d$ per month it was ingested ${ }^{(17)}$ : daily intake 
$=30 \cdot 4 ; 4-6$ times $/$ week $=21 \cdot 7 ; 1-3$ times $/$ week $=8 \cdot 7 ; 2-3$ times $/$ month $=2 \cdot 5 ; 1$ time $/$ month $=1$ and never $=0 \mathrm{~d} /$ month. Greenlandic food items were scored positively, imported food items were scored negatively. The sum of food frequency scores was calculated for all food items ingested by each participant. Participants were then categorised in three diet groups according to a scale on which a frequency score of $100 \%$ represented a diet consisting of solely Inuit food items and a score of $0 \%$ represented a diet consisting of solely imported food items. The three diet groups were composed as follows: diet group 1 had Inuit food frequency scores of $>60 \%$; diet group 2 had scores of $40-60 \%$; and diet group 3 had scores $<40 \%$.

\section{Assays}

Plasma 25-hydroxyvitamin D. Plasma 25-hydroxyvitamin $\mathrm{D}_{3}$ and $\mathrm{D}_{2}$ were analysed by isotope dilution liquid chromatography-tandem mass spectrometry (LC-MS/MS) and calibrated to the National Institute of Standards and Technology standard ${ }^{(18)}$, as described in detail previously ${ }^{(15)}$.

High-sensitivity C-reactive protein. High-sensitivity CRP (hsCRP) levels were measured with a highly sensitive, latex particle-enhanced immunoturbidimetric assay (DAKO) with a measuring range of $0 \cdot 2-80 \mathrm{mg} / \mathrm{l}$ and with a lower detection limit of $0.03 \mathrm{mg} / 1$.

Chitinase-3-like protein 1. Plasma YKL-40 levels were measured with an ELISA method (Quidel). The measuring range of the assay was $20-300 \mathrm{ng} / \mathrm{ml}$, with intra- and interassay $\mathrm{CV}$ of 5.8 and $6.0 \%$, respectively.

Serum from the participants was analysed in a random order with participant characteristics blinded to the laboratories for all assays.

\section{Statistics}

Results are given as number of participants in groups, percentages, medians and quartiles. Groups were compared using the $\chi^{2}$ test and one-way ANOVA. The unpaired-samples $t$ test was used for the pairwise comparison. The Kruskal-Wallis test was used for comparison of levels between several groups, and Kendall's tau rank correlation coefficient was used to describe a relationship between groups. YKL-40 and hsCRP were logarithmically transformed for the linear regression analysis using the natural logarithm for calculations. Dependent variables were YKL-40 and hsCRP; explanatory variables were age, BMI, sex, smoking, alcohol intake, diet, vitamin $\mathrm{D}$ and ethnicity.

MedStat software (Astra) was used for the random selection of participants in Nuuk. Data were processed and analysed using Stata version 13.1 software (StataCorp.). Two-sided $P$ values less than 0.05 were considered significant.

\section{Results}

The 535 men and women were aged 50-69 years. Clinical characteristics of the participants are shown in Table 1 . The group of non-Inuit and mixed ethnicity ( $n$ 101) consisted of

Table 1. Descriptives of participants in the study among populations in West and East Greenland living on traditional Inuit food and imported food items (Numbers of participants and percentages)

\begin{tabular}{|c|c|c|c|c|c|c|c|}
\hline & \multicolumn{6}{|c|}{ Ethnicity } & \multirow[b]{3}{*}{$P^{\star}$} \\
\hline & \multicolumn{2}{|c|}{ Inuit } & \multicolumn{2}{|c|}{ Mix } & \multicolumn{2}{|c|}{ Non-Inuit } & \\
\hline & $n$ & $\%$ & $n$ & $\%$ & $n$ & $\%$ & \\
\hline \multicolumn{8}{|l|}{ Age } \\
\hline $50-59$ years & 259 & 60 & 6 & 86 & 79 & 84 & \multirow[t]{2}{*}{$<0.001$} \\
\hline $60-69$ years & 175 & 40 & 1 & 14 & 15 & 16 & \\
\hline \multicolumn{8}{|l|}{ Sex } \\
\hline Men & 229 & 53 & 5 & 71 & 75 & 80 & \multirow[t]{2}{*}{$<0.001$} \\
\hline Women & 205 & 47 & 2 & 29 & 19 & 20 & \\
\hline \multicolumn{8}{|l|}{ Alcohol† } \\
\hline $0-7$ & 274 & 64 & 5 & 72 & 51 & 55 & \multirow[t]{3}{*}{0.45} \\
\hline $8-14$ & 95 & 22 & 1 & 14 & 24 & 26 & \\
\hline $15+$ & 57 & 14 & 1 & 14 & 18 & 19 & \\
\hline \multicolumn{8}{|l|}{ Smoking } \\
\hline Never & 56 & 13 & 1 & 14 & 25 & 27 & \multirow[t]{3}{*}{0.002} \\
\hline Past & 49 & 11 & 1 & 14 & 17 & 18 & \\
\hline Present & 328 & 76 & 5 & 72 & 52 & 55 & \\
\hline \multicolumn{8}{|c|}{ Vitamin D supplements $\ddagger$} \\
\hline Intake & 23 & 5 & 0 & 0 & 22 & 23 & \multirow[t]{2}{*}{$<0.001$} \\
\hline No intake & 411 & 95 & 7 & 100 & 72 & 77 & \\
\hline \multicolumn{8}{|l|}{ BMI } \\
\hline$<30 \mathrm{~kg} / \mathrm{m}^{2}$ & 331 & 82 & 7 & 100 & 77 & 82 & \multirow[t]{2}{*}{0.46} \\
\hline$>30 \mathrm{~kg} / \mathrm{m}^{2}$ & 73 & 18 & 0 & 0 & 17 & 18 & \\
\hline
\end{tabular}

* Compared using the $\chi^{2}$ test.

†Units per week where one unit equals $8 \mathrm{~g}$ alcohol.

‡ Daily intake. 


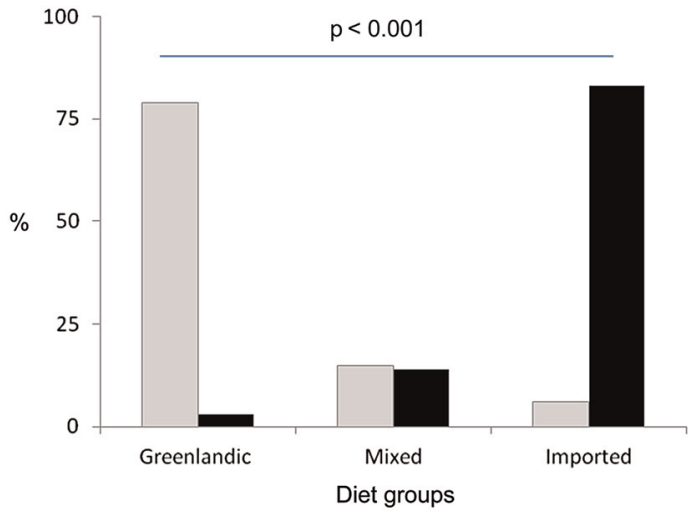

Fig. 1. The distribution (\%) of Inuit (:) and non-Inuit ( $\square$ ) in the three diet groups.

more men and they were slightly younger than the group of Inuit $(n$ 434). More Inuit were smokers.

Fig. 1 illustrates the difference in intake of the traditional Greenlandic diet between the two ethnic groups who participated in the study. Markedly more Inuit than non-Inuit had a frequent intake of the traditional Greenlandic diet (79\%) while the reverse was the case for non-Inuit with $83 \%$ living mainly on imported foods $(P<0 \cdot 001)$.

The levels of vitamin D, YKL-40 and hsCRP for the three diet groups, mainly Greenlandic diet, mixed diet and mainly imported diet are shown in Table 2. Vitamin D as well as the inflammatory markers YKL-40 and hsCRP were markedly higher in the group living on the traditional Greenlandic diet when compared with the mixed and imported diet in the overall comparison (Table 2). In the pairwise comparison, vitamin $\mathrm{D}$ differed markedly between the three individual diet groups (Table 2). Findings were similar for YKL-40. The difference in hsCRP between the diet groups was marked only when comparing those with a high intake of the traditional Greenlandic diet and those with a high intake of imported food items while not when the group with the mixed diet was included in the comparisons (Table 2).

Table 3 shows the influence of a number of factors on the two markers of inflammation. YKL-40 was influenced by age, BMI, smoking, diet and ethnicity but not by vitamin D in the crude comparisons. The adjusted comparisons added an influence of vitamin D and alcohol on YKL-40 with slightly decreased YKL-40 level with rising vitamin D. Interestingly, hsCRP was not influenced by vitamin D in the crude or adjusted comparison.

Ethnicity influenced YKL-40 and hsCRP, as both were clearly higher in Inuit than in non-Inuit both in the crude and adjusted comparisons (Table 3). Also, the traditional Inuit diet influenced YKL-40 and hsCRP with the highest levels among participants living on the traditional Inuit diet in both the crude as well as the adjusted analysis. The findings were similar for age with higher levels of both markers of inflammation with higher age though the influence was less pronounced.

The association between vitamin $\mathrm{D}$ on the two markers of inflammation is further detailed in Fig. 2, which shows YKL-40 (Fig. 2(a) and (c)) and hsCRP (Fig. 2(b) and (d)) by two diet groups and for Inuit participants only. It illustrates that YKL-40 levels differed between vitamin D-level groups for the Inuit participants living on the traditional Inuit diet and participants living on the mixed diet but not for those living on imported foods (data not shown). There was a distinct decrease in YKL-40 levels with rising vitamin D levels for Inuit living on the traditional Greenlandic diet (Kendall's tau, $P=0.002)$ and for those living on the mixed diet $(P=0.046)$. There was no difference in hsCRP with vitamin $\mathrm{D}$ level for either of the diet groups (Fig. 2).

\section{Discussion}

This is the first population-based survey to study both vitamin $\mathrm{D}$ and markers of inflammation in relation to the traditional marine diet among Inuit and non-Inuit in Greenland. The main findings were markedly higher levels of the inflammatory markers YKL-40 and hsCRP as well as levels of vitamin D among participants with the highest intake of the traditional Inuit diet. Interestingly, we found only a limited association between vitamin $\mathrm{D}$ and markers of inflammation.

Inflammation is the net result of both anti- and proinflammatory factors. Increased inflammation has been shown in Inuit with a high intake of the traditional marine $\operatorname{diet}^{(16)}$ and with a high alcohol intake ${ }^{(19)}$ although the latter did not include dietary habits in their report. We hypothesised that vitamin $\mathrm{D}$ from the marine diet had an inflammationdampening effect.

Table 2. Vitamin $D$ and markers of inflammation in populations in Greenland divided into three diet groups (Medians and interquartile ranges (IQR))

\begin{tabular}{|c|c|c|c|c|c|c|c|c|c|c|}
\hline & \multicolumn{6}{|c|}{ Diet group } & \multirow[b]{3}{*}{$P^{\star}$} & \multirow[b]{3}{*}{$P+$} & \multirow[b]{3}{*}{$P \ddagger$} & \multirow[b]{3}{*}{$P \S$} \\
\hline & \multicolumn{2}{|c|}{ Greenlandic } & \multicolumn{2}{|c|}{ Mixed } & \multicolumn{2}{|c|}{ Imported } & & & & \\
\hline & Median & IQR & Median & IQR & Median & IQR & & & & \\
\hline Vitamin D (nм) & $74 \cdot 2$ & $59 \cdot 8-93 \cdot 8$ & 69.8 & $53 \cdot 7-84 \cdot 1$ & 52.9 & $33 \cdot 7-66 \cdot 8$ & $<0.001$ & 0.014 & $<0.001$ & $<0.001$ \\
\hline YKL-40॥ (ng/ml) & $130 \cdot 1$ & $79 \cdot 8-223 \cdot 4$ & $95 \cdot 3$ & $64 \cdot 0-195 \cdot 2$ & $60 \cdot 8$ & $46 \cdot 1-122 \cdot 4$ & $<0.001$ & 0.021 & $<0.001$ & $<0.001$ \\
\hline hsCRP\| (mg/l) & 1.6 & $1 \cdot 1-4 \cdot 0$ & 1.4 & $0.7-3.5$ & 1.3 & $0.5-2.3$ & 0.002 & NS & $<0.001$ & NS \\
\hline
\end{tabular}

YKL-40, chitinase-3-like protein 1; hsCRP, high-sensitivity C-reactive protein.

* Compared using one-way ANOVA.

$\dagger t$ test, Greenlandic food $v$. mixed food.

$\ddagger t$ test, Greenlandic food $v$. imported food.

$\S t$ test, mixed food $v$. imported food.

II In-transformed for analysis. 


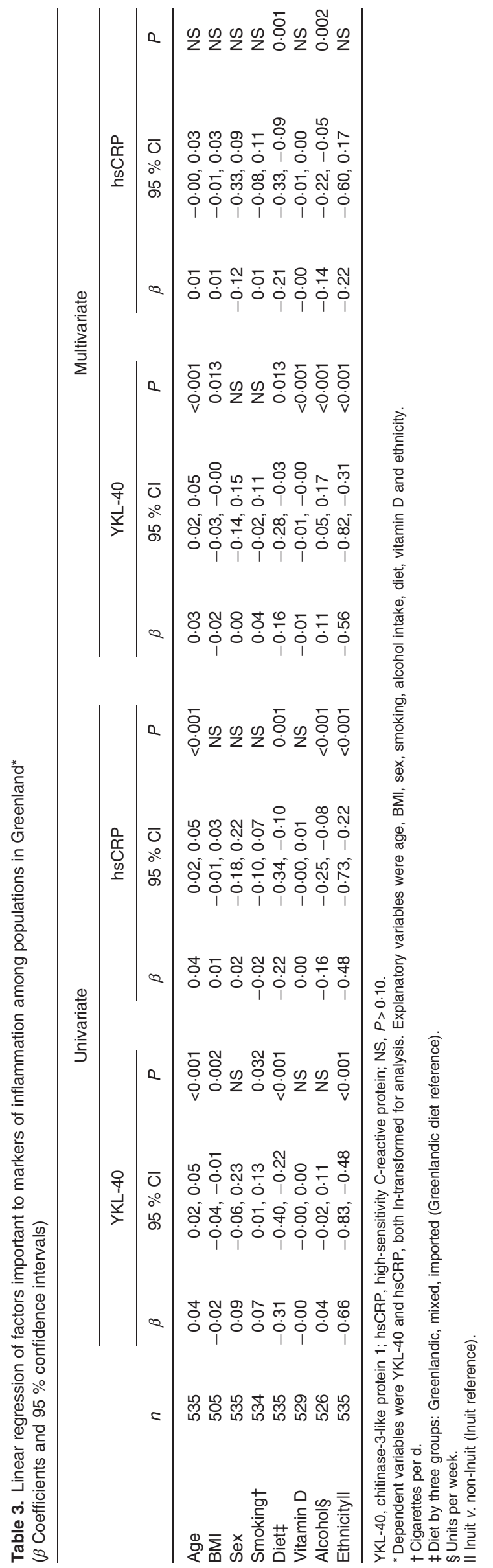

In the present report we measured two different markers of inflammation to portray the sum of inflammation. However, our data did not fully support our hypothesis. Thus, it may be speculated that the traditional Greenlandic diet may contain both anti- and pro-inflammatory components and that the latter dominates the inflammatory balance.

Sources of vitamin D in the Arctic include both dietary and dermal. Dermal vitamin D synthesis was hypothesised to be low both due to limited intensity of UVB light and due to low sun exposure of the skin as the general temperature discourages sunbathing, even during summer months. However, sun exposure does influence vitamin D levels at high latitudes as demonstrated in a study of Inuit and non-Inuit in North Greenland ${ }^{(20)}$. In that study Andersen et al. found indication of dermal vitamin $\mathrm{D}$ production in addition to the diet as a source of vitamin D. Still, the dominant contributor to vitamin D in populations in Greenland is the diet. Thus, previous studies support our finding of higher vitamin D levels among subjects with a high intake of Greenlandic food items. Rejnmark et al. ${ }^{(21)}$ surveyed Inuit living in the capital city Nuuk and Inuit and Danes living in Denmark. They reported higher vitamin D levels among participants with an intake of traditional Greenlandic food items compared with a Westernised diet. The influence of the traditional Inuit marine diet on vitamin $\mathrm{D}$ was detailed in a population-based study of Inuit and non-Inuit living in West and East Greenland ${ }^{(15)}$. The intake of the traditional marine diet contributed markedly to the vitamin D levels. Specifically, seal and whale were major contributors to vitamin D. The influence of the traditional Inuit marine diet on vitamin $\mathrm{D}$ has also been demonstrated in a recent study by Nielsen et al. ${ }^{(22)}$. They report a decrease in vitamin $\mathrm{D}$ levels over time along with decreasing intake of traditional Inuit food items. Hence, the influence of the traditional Inuit marine diet on vitamin D was documented in our study as well as in previous studies of Inuit in Greenland.

Vitamin D is speculated to have anti-inflammatory capacities. A correlation between vitamin D insufficiency and inflammatory diseases have been reported in a number of studies. These studies included patients with rheumatoid arthritis ${ }^{(23)}$, type 2 diabetes mellitus ${ }^{(24)}$, inflammatory bowel disease ${ }^{(25)}$, CVD $^{(26)}$, acute infections ${ }^{(27)}$, and healthy older adults ${ }^{(7,28)}$. Hence, a potential anti-inflammatory role of vitamin D is extensively documented in observational studies. However, this association has been difficult to confirm in randomised controlled studies. Some have found an effect of vitamin D on inflammation ${ }^{(29,30)}$ while others have not ${ }^{(31-34)}$. The explanation for this discrepancy remains to be settled. The hypothesised inflammation-dampening effect of vitamin $\mathrm{D}$ was limited in our study, and also in the adjusted analysis. It could be speculated whether this anti-inflammatory effect is dimmed by other factors.

The traditional Greenlandic diet is mainly of marine origin and is dominated by fish and marine mammals ${ }^{(11)}$. The diet provides a range of nutrients to the population including vitamins $\mathrm{A}$ and $\mathrm{D}, \mathrm{Fe}, \mathrm{I}, \mathrm{P}, \mathrm{Se}$ and $n-3$ fatty $\operatorname{acids}^{(13,35,36)}$. However, the marine mammals and fish contain high levels of persistent organic pollutants $(\mathrm{POPs})^{(35,37,38)}$. This conflict 


\section{Inuit diet}

(a)

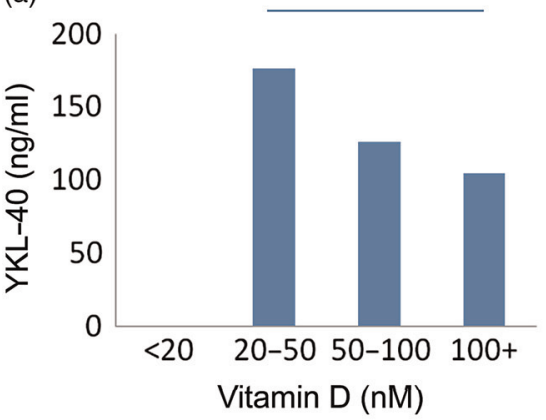

(b)

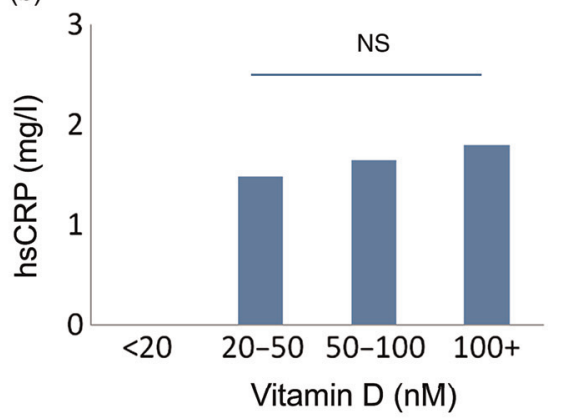

Mixed diet
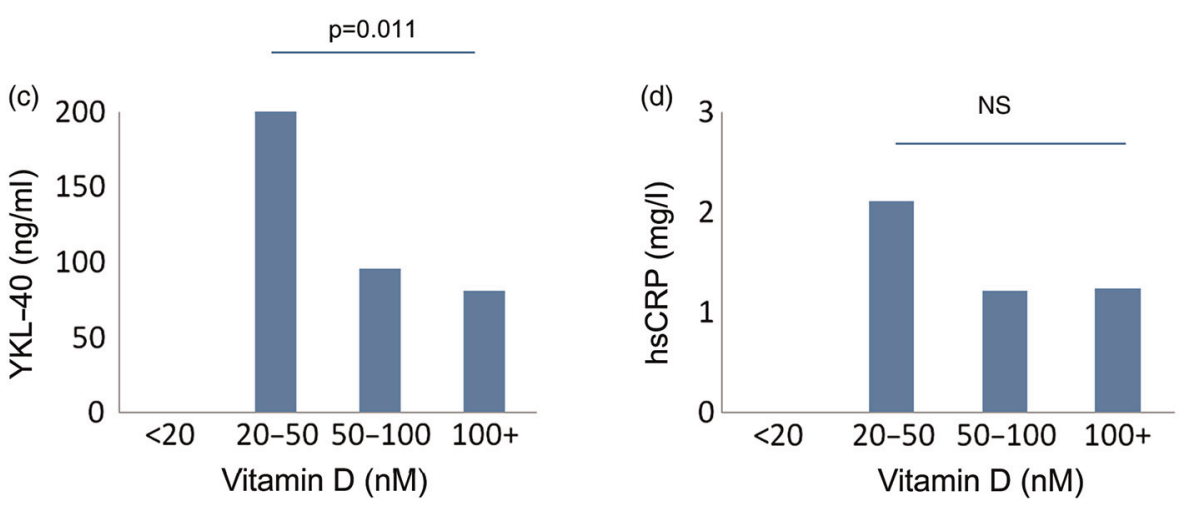

Fig. 2. Vitamin D and markers of inflammation in serum from Inuit in the two diet groups with an intake of mainly Inuit diet and a mixed diet. Very few Inuit lived on imported food items (number of participants were 0, 4, 17 and 3 in the vitamin D groups <20, 20-50, 50-100 and 100+ nm). YKL-40, chitinase-3-like protein 1; hsCRP, high-sensitivity C-reactive protein.

with a diet that contributes both important nutrients as well as harmful substances has been labelled 'the Arctic dilemma ${ }^{6(35,37)}$. POPs have an array of known effects in humans, including reduction of humeral immune response ${ }^{(39)}$ with increased inflammation ${ }^{(40)}$. Thus, POPs have been shown to induce oxidative stress in vitro in endothelial cells ${ }^{(41)}$, in vivo in rats ${ }^{(42)}$ and Kim et al. ${ }^{(40)}$ found increased inflammation in a study of POPs and inflammation in non-diabetic adults. It may thus be hypothesised that a pro-inflammatory effect of POPs explains the limited anti-inflammatory effect of vitamin D from the traditional Greenlandic marine diet in our study.

We used FFQ to assess the intake of the traditional Inuit diet and imported food items. FFQ do have limitations. However, FFQ is considered a valid method for assessing the intake of nutrients ${ }^{(43)}$. The FFQ used in the present study was interview-based and the questions were targeted well-known and clearly defined Greenlandic food items. Furthermore, it was validated in this population using crosscheck questionnaires and iodine as a biomarker ${ }^{(13)}$. This clearly supports our use of the FFQ method. More non-Inuit than Inuit used supplements but the number of users was limited and supplement use did not corrupt our results. The population invited was limited in size. However, the total population of all of Greenland is only about 56000 and the participation rate in our study was $95 \%$. The groups selected represent the diversity in dietary habits in all of Greenland with participants from the capital city as well as participants from a mediumsized town and from the most remote settlements in
Greenland. Our study was strengthened by the dual approach to describe inflammation with two different inflammatory markers. YKL-40 is produced in the endothelial cells while hsCRP is produced in the hepatocytes ${ }^{(2)}$. Hence, the inflammatory process is documented by two different approaches. Residual confounding cannot be ruled out. However, we have re-run the regression analysis with only age and ethnicity in addition to vitamin $\mathrm{D}$ as explanatory variables and the two markers of inflammation as dependent variables. The results of these analyses were similar with a slight variation in coefficients but similar slope and significance levels. Thus, any residual confounding is likely to have limited influence on the results and hence not alter the conclusions.

In conclusion, the traditional Inuit diet contains important nutrients such as vitamin $\mathrm{D}$ and $n$ - 3 fatty acids that may act in an anti-inflammatory fashion. This favours the intake of the traditional marine diet. Still, based on our findings it may be hypothesised that pro-inflammatory factors are present in the marine diet. This needs to be elucidated to inform the discussion on 'the Arctic dilemma': to eat or not to eat traditional marine food items.

\section{Acknowledgements}

The authors thank Ulla Kjaerulff-Hansen, Tonni Loeve Hansen and Hanne Dorthe Mogensen, Endocrine Research Laboratory, Copenhagen University Hospital Herlev, Denmark, for skilful assistance with the laboratory work. 
This work was supported by grants from the Greenland Government, the Karen Elise Jensen Foundation and the Aase and Ejnar Danielsens Foundation.

The authors' contributions to the paper were as follows: L. K. S.: project conception, analysis of data and writing of the manuscript; E. C. B.-J.: study question development, evaluation of data and reviewing of the manuscript; P. L.: project conception, study design, raising of funds, data collection and reviewing of the manuscript; H. V.: study question development and reviewing of the manuscript; S. A.: conception of idea, study design, raising of funds, data collection, evaluation of data and reviewing of the manuscript.

The authors declare that there are no financial or personal conflicts of interest.

\section{References}

1. Lopez AD, Mathers CD, Ezzati M, et al. (2006) Global and regional burden of disease and risk factors, 2001: systematic analysis of population health data. Lancet 367, 1747-1757.

2. Hansson GK (2005) Inflammation, atherosclerosis, and coronary artery disease. N Engl J Med 352, 1685-1695.

3. Rathcke CN \& Vestergaard H (2009) YKL-40 - an emerging biomarker in cardiovascular disease and diabetes. Cardiovasc Diabetol 8, 61.

4. Kucur M, Isman FK, Karadag B, et al. (2007) Serum YKL-40 levels in patients with coronary artery disease. Coron Artery Dis 18, 391-396.

5. Michelsen AE, Rathcke CN, Skjelland M, et al. (2010) Increased YKL-40 expression in patients with carotid atherosclerosis. Atherosclerosis 211, 589-595.

6. Zittermann A, Schleithoff SS \& Koerfer R (2005) Putting cardiovascular disease and vitamin $\mathrm{D}$ insufficiency into perspective. $\mathrm{Br} J$ Nutr 94, 483-492.

7. Laird E, McNulty H, Ward M, et al. (2014) Vitamin D deficiency is associated with inflammation in older Irish adults. J Clin Endocrinol Metab 99, 1807-1815.

8. Durup D, Jørgensen HL, Christensen J, et al. (2015) A reverse J-shaped association between serum 25-hydroxyvitamin D and cardiovascular disease mortality - the CopD study. J Clin Endocrinol Metab 100, 2339-2346.

9. Brandenburg VM, Vervloet MG \& Marx N (2012) The role of vitamin $\mathrm{D}$ in cardiovascular disease: from present evidence to future perspectives. Atherosclerosis 225, 253-263.

10. Kjaergaard M, Andersen S, Holten M, et al. (2009) Low occurrence of ischemic heart disease among Inuit around 1963 suggested from ECG among 1851 East Greenland Inuit. Atherosclerosis 203, 599-603.

11. Bang HO, Dyerberg J \& Sinclair HM (1980) The composition of the Eskimo food in north western Greenland. Am J Clin Nutr 33, 2657-2661.

12. Jorgensen ME, Bjerregaard P, Kjaergaard JJ, et al. (2008) High prevalence of markers of coronary heart disease among Greenland Inuit. Atherosclerosis 196, 772-778.

13. Andersen S, Hvingel B, Kleinschmidt K, et al. (2005) Changes in iodine excretion in 50-69-y-old denizens of an Arctic society in transition and iodine excretion as a biomarker of the frequency of consumption of traditional Inuit foods. Am J Clin Nutr 81, 656-663.

14. Dahl-Petersen IK, Jorgensen ME \& Bjerregaard P (2011) Physical activity patterns in Greenland: a country in transition. Scand J Public Health 39, 678-686.

15. Andersen S, Laurberg P, Hvingel B, et al. (2013) Vitamin D status in Greenland is influenced by diet and ethnicity: a population-based survey in an Arctic society in transition. Br J Nutr 109, 928-935.
16. Schaebel LH, Vestergaard H, Laurberg P, et al. (2013) Intake of traditional Inuit diet vary in parallel with inflammation as estimated from YKL-40 and hsCRP in Inuit and non-Inuit in Greenland. Atherosclerosis 228, 496-501.

17. Pars T, Osler M \& Bjerregaard P (2001) Contemporary use of traditional and imported food among Greenlandic Inuit. Arctic 54, 22-31.

18. Hojskov CS, Heickendorff L \& Moller HJ (2010) High-throughput liquid-liquid extraction and LCMSMS assay for determination of circulating $25(\mathrm{OH})$ vitamin $\mathrm{D}_{3}$ and $\mathrm{D}_{2}$ in the routine clinical laboratory. Clin Chim Acta 411, 114-116.

19. Nojgaard C, Johansen JS, Bjerregaard P, et al. (2015) Plasma YKL-40 in Inuit and Danes. Alcohol Alcohol 50, 11-17.

20. Andersen S, Jakobsen A \& Laurberg P (2013) Vitamin D status in North Greenland is influenced by diet and season: indicators of dermal 25-hydroxy vitamin D production north of the Arctic Circle. Br J Nutr 110, 50-57.

21. Rejnmark L, Jorgensen ME, Pedersen MB, et al. (2004) Vitamin D insufficiency in Greenlanders on a westernized fare: ethnic differences in calcitropic hormones between Greenlanders and Danes. Calcif Tissue Int 74, 255-263.

22. Nielsen NO, Jorgensen ME, Friis H, et al. (2014) Decrease in vitamin D status in the Greenlandic adult population from 1987-2010. PLOS ONE 9, e112949.

23. Di Franco M, Barchetta I, Iannuccelli C, et al. (2015) Hypovitaminosis D in recent onset rheumatoid arthritis is predictive of reduced response to treatment and increased disease activity: a 12 month follow-up study. BMC Musculoskelet Disord 16, 53.

24. Knekt P, Laaksonen M, Mattila C, et al. (2008) Serum vitamin D and subsequent occurrence of type 2 diabetes. Epidemiology 19, 666-671.

25. Jahnsen J, Falch JA, Mowinckel P, et al. (2002) Vitamin D status, parathyroid hormone and bone mineral density in patients with inflammatory bowel disease. Scand J Gastroenterol 37, 192-199.

26. Wang TJ, Pencina MJ, Booth SL, et al. (2008) Vitamin D deficiency and risk of cardiovascular disease. Circulation 117, 503-511.

27. Berry DJ, Hesketh K, Power C, et al. (2011) Vitamin D status has a linear association with seasonal infections and lung function in British adults. Br J Nutr 106, 1433-1440.

28. De Vita F, Lauretani F, Bauer J, et al. (2014) Relationship between vitamin $\mathrm{D}$ and inflammatory markers in older individuals. Age (Dordr) 36, 9694.

29. Asemi Z, Samimi M, Tabassi Z, et al. (2013) Vitamin D supplementation affects serum high-sensitivity C-reactive protein, insulin resistance, and biomarkers of oxidative stress in pregnant women. J Nutr 143, 1432-1438.

30. Witham MD, Dove FJ, Khan F, et al. (2013) Effects of vitamin D supplementation on markers of vascular function after myocardial infarction - a randomised controlled trial. Int J Cardiol 167, 745-749.

31. Muldowney S, Lucey AJ, Hill TR, et al. (2012) Incremental cholecalciferol supplementation up to $15 \mu \mathrm{g} / \mathrm{d}$ throughout winter at $51-55^{\circ}$ $\mathrm{N}$ has no effect on biomarkers of cardiovascular risk in healthy young and older adults. J Nutr 142, 1519-1525.

32. Wood AD, Secombes KR, Thies F, et al. (2012) Vitamin $\mathrm{D}_{3}$ supplementation has no effect on conventional cardiovascular risk factors: a parallel-group, double-blind, placebo-controlled RCT. J Clin Endocrinol Metab 97, 3557-3568.

33. Yiu YF, Yiu KH, Siu CW, et al. (2013) Randomized controlled trial of vitamin D supplement on endothelial function in patients with type 2 diabetes. Atherosclerosis 227, 140-146.

34. Wamberg L, Kampmann U, Stodkilde-Jorgensen H, et al. (2013) Effects of vitamin D supplementation on body fat accumulation, inflammation, and metabolic risk factors in obese adults with low vitamin D levels - results from a randomized trial. Eur J Intern Med 24, 644-649.

35. Deutch B, Dyerberg J, Pedersen HS, et al. (2007) Traditional and modern Greenlandic food - dietary composition, nutrients and contaminants. Sci Total Environ 384, 106-119.

36. Bjerregaard P \& Jeppesen C (2010) Inuit dietary patterns in modern Greenland. Int J Circumpolar Health 69, 13-24. 
37. Bonefeld-Jorgensen EC (2010) Biomonitoring in Greenland: human biomarkers of exposure and effects - a short review. Rural Remote Health 10, 1362.

38. Seabert TA, Pal S, Pinet BM, et al. (2014) Elevated contaminants contrasted with potential benefits of omega-3 fatty acids in wild food consumers of two remote first nations communities in northern Ontario, Canada. PLOS ONE 9, e90351.

39. Grandjean P, Andersen EW, Budtz-Jorgensen E, et al. (2012) Serum vaccine antibody concentrations in children exposed to perfluorinated compounds. JAMA 307, 391-397.

40. Kim KS, Hong NS, Jacobs DR Jr, et al. (2012) Interaction between persistent organic pollutants and C-reactive protein in estimating insulin resistance among non-diabetic adults. J Prev Med Public Health 45, 62-69.

41. Hennig B, Hammock BD, Slim R, et al. (2002) PCB-induced oxidative stress in endothelial cells: modulation by nutrients. Int J Hyg Environ Health 205, 95-102.

42. Hong MY, Lumibao J, Mistry P, et al. (2015) Fish oil contaminated with persistent organic pollutants reduces antioxidant capacity and induces oxidative stress without affecting its capacity to lower lipid concentrations and systemic inflammation in rats. J Nutr 145, 939-944.

43. Serra-Majem L, Pfrimer K, Doreste-Alonso J, et al. (2009) Dietary assessment methods for intakes of iron, calcium, selenium, zinc and iodine. Br J Nutr 102, Suppl. 1, S38-S55. 